\title{
НЕКОТОРЫЕ ПРОБЛЕМЫ ОЦЕНКИ ПОТЕРЬ НАСЕЛЕНИЯ В ГОДЫ КОЛЛЕКТИВИЗАЦИИ
}

\author{
СЕРГЕЙ МАКСУДОВ
}

\begin{abstract}
После открытия советских архивов в конце 1980-х годов многие исследователи считали результаты переписи 1939 г. малодостоверными, поскольку, по их мнению, статистики, проводивщие перепись, помня печальную судьбу организаторов переписи 1937 г., признанной вредительской, и понимая, что власти хотят видеть большую численность населения, пошли на фальсификацию результатов. Наше исследование показывает, что огромные усилия, вложенные в точное проведение переписи, не пропали даром. И сотни тысяч переписчиков, от которых требовали найти каждого человека, проживающего на их участке, действительно старательно выполняли свою работу. Изучение архивных материалов позволяет понять, как при обработке были получены результаты, переданные правительству и озвученные руководством страны. Исследование показало, что перепись 19392. была действительно точной, более достоверной, чем предшествующие и последующие переписи. И даже однопроцентная поправка на неполноту учета, сделанная, казалось бы, без серьезных обоснований, не является ошибочной, поскольку число лиц, уклонявшихся от переписи (из-за уголовного прошлого, отсутствия прописки по месту жительства, болезни или по другим причинам) заведомо превышает 1\%. При этом от введения такой поправки следует отказаться, поскольку ее не было в других переписях, а для получения достоверных результатов необходимо, чтобы использованные данные имели примерно равную точность. Также из переписи были нами исключень лица, которые встретились со счетчиком вне дома, но неверно указали в контрольных бланках место своего постоянного проживания. В архивных таблицах эта категория жителей сопровождалась указанием: «Может быть включено в качестве постоянного или временного населения». Эта надпись сделана людьми, составлявшими документ для своего начальства и хорошо знавшими все материаль и степень достоверности этих данных. И то, как сделана эта гипотетическая рекомендация, позволяет считать, что сами составители полагали, что «может быть и не включено».
\end{abstract}

Таким образом, численность населения по переписи 1939 г. принимается почти на 2 млн меньше, чем в публикациях ЦСУ советского времени. С ичелью приведения результатов переписей примерно к равной надежности было необходимо ввести определенные коррекции в переписи 1926 г. (из-за отсутствия контрольньх бланков и контрольного обхода, неодинаковой продолжительности переписи в городе и в селе, а также из-за предполагаемой многими исследователями и полученной нами в процессе расчета неполноты учета переписью малолетних детей) и 1937 г. (из-за иной методики ее проведения). Сделанные поправки позволяют получить более надежную оценку потерь населения СССР от коллективизации и репрессий в период 1929-1939 г2.

Ключевые слова: перепись населения, коллективизация, потери населения

СЕРГЕЙ МАКСУДОВ, ДЭВИС ЦЕНТР РОССИЙСКИХ И ЕВРАЗИЙСКИХ ИССЛЕДОВАНИЙ ГАРВАРДСКОГО УНИВЕРСИТЕТА. США. Е-mail: babyonys@fas.harvard.edu СТАТЬЯ ПОСТУПИЛА В РЕДАКЦИЮ В ИЮНЕ 2015 Г. 
Одной из самых страшных демографических катастроф XX века была коллективизация: разрушение быта, традиций, социальных и производственных отношений сельских жителей. Она завершилась чудовищным голодом 1932-34 гг., носившим в значительной степени искусственный характер. Долгое время оценкой размеров этих потерь занимались лишь эмигрантские и западные ученые. Они опирались на свидетельства очевидцев, рассказы перебежчиков, а также на данные переписей и неполные сведения советской статистики 30-х годов, не имея при этом представления о степени достоверности этих данных. Яркой иллюстрацией такого подхода служит книга Роберта Конквеста [Conquest 1986], который использует утверждения Сталина (ежегодный прирост 3 млн человек), прогнозы Госплана (180,7 млн на начало 1938 г.), рассказы очевидцев (156 млн по переписи 1937 г. - Антонов-Овсеенко) и получает 14,5 млн погибших ${ }^{1}$. Наиболее строгой научной работой явился классический труд Франка Лоримера, оценившего по тем же советским данным потери в 5,5 млн человек [Lorimer 1946: 134]. Подробнее об этих и других исследованиях советского времени: [Демографическая модернизация... 2006: 406-438; Уиткрофт 2001: 866-887; Максудов 1987: 369-393].

В 1944 г. комиссия ЦСУ во главе с П.И. Поповым составила баланс населения за 1926-1939 гг. Она сопоставила прирост населения за 12 лет по данным ЗАГС (рождено 61104 тыс., умерло 35204 тыс., естественный прирост 25,9 млн человек) с разницей численности населения по переписям (23,5 млн). Расхождение в 2,4 млн авторы распределили равномерно по годам, увеличив смертность за каждый год на 6,7\% [Андреев и др. 1993: 40, 118; ЦСУ 1964].

В 1964 г., когда оценки численности населения в 30-е годы перестали быть политически актуальными, статистики ЦСУ С.А. Бекунова и Е.В. Родионова проделали тщательное исследование неполноты текущего учета населения в 1926-1939 гг. По их расчетам, число родившихся за 12 лет и 1 месяц увеличилось с 61194 тыс. до 70122 тыс. человек (14,8\%), а число умерших соответственно с 35204 тыс. до 40309 тыс. человек (14,5\%). Естественный прирост при этом составил 29813 тыс., на 6284 тыс. больше, чем изменение численности населения между переписями 1926 и 1939 г. Эта цифра является повышенной убылью населения, оценкой потерь. Подавляющее большинство этих потерь (85\%) авторы отнесли к периоду коллективизации, в том числе на годы голода (1932-1935) приходится $65 \%{ }^{2}$.

Результаты, полученные Бекуновой и Родионовой, представляются необычайно важными. В их распоряжении был большой фактический материал, они работали в отделе, сотрудники которого хорошо представляли степень достоверности имеющихся сведений и

\footnotetext{
${ }^{1}$ 6,5 млн погибших в результате раскулачивания, 1 млн - казахская катастрофа, 5 млн - гибель от голода в 1932-33 гг. на Украине, 1 млн - Северный Кавказ, 1 млн - в других местах [Conquest 1986: 299-307].

2 В Записке [ЦСУ 1964] поправки по годам довольно странного вида приведены в процентах (1927 г. - 10\%, 1928-1931 гг. $-19,7 \%, 1932$ г. $-21,3 \%, 1933$ г. - 19,7\%, 1934-35 гг. - 21,3\%, 1936-37 гг. - 5\%, 1938 г. - без поправок), всего почемуто 97\%. Можно предположить, что первоначально поправки были рассчитаны для округленной суммарной численности (6,3 млн) и выглядели следующим образом: 1927 г. - 630 тыс., 1928-31 и 1933 г. - по 1240 тыс., 1932 и 1934-35 гг. - по 1340 тыс., 1935-36 гг. - 315 тыс. Итого 6105 тыс. человек. Вместе с пропущенными 3\%, которые мы считаем принадлежащими к 1933 г., получаем исходную сумму поправок 6284 тыс.
} 
имели большой опыт расчетов численности населения в прошлом. Так, например, они подсчитали и опубликовали численность населения СССР 1 мая 1956 г. в городе и селе по отдельным республикам, областям и большим городам. Расхождение этой оценки по стране (200,2 млн) с результатами, полученными по переписи 1959 г. (198,8 млн) составило всего 1,4 млн (0,7\%) [Народное хозяйство 1956: 17-32; Население СССР 1975: 10-13]. Эта фантастически точная оценка была сделана через 17 лет после предыдущей переписи, после страшной войны, которая унесла жизни десятков миллионов, многие десятки миллионов сдвинула с места и присоединила территории опять же с десятками миллионов человек.

С открытием советских архивов в научный оборот были введены многочисленные документы ЦУНХ и ЦСУ за ряд лет, а также рабочие материалы обработки переписей 1937 и 1939 г. Множество сведений об уровне смертности в различных регионах страны в разные годы опубликовал Ст. Уиткрофт. Однако он по-прежнему оценивает потери коллективизации по Лоримеру (5,7 млн человек) [Davies, Wheatcroft 2004: 408-421]. По заданию М.С. Горбачева коллектив демографов Евгений Андреев, Леонид Дарский и Татьяна Харькова по специально построенной демографической модели оценили потери в годы коллективизации и Великой Отечественной войны. Они откорректировали результаты переписей 1926, 1937 и 1939 г. и заметно увеличили сведения о рождаемости и смертности по сравнению с расчетами Е.В. Родиной и С.А. Бекуновой (таблица 1).

Таблица 1. Движение населения в 1927-38 гг. по ЦСУ 1964 и Андрееву, Дарскому, Харьковой, тыс. человек

\begin{tabular}{|c|c|c|c|c|c|c|c|}
\hline \multirow{2}{*}{ Годы } & \multicolumn{3}{|c|}{ ЦСУ 1964} & \multicolumn{3}{|c|}{ Андреев, Дарский, Харькова } & \multirow{2}{*}{ Разница приростов } \\
\hline & родилось & умерло & прирост & родилось & умерло & прирост & \\
\hline 1927 & 6655 & 3582 & 3073 & 6950 & 3984 & 2966 & 107 \\
\hline 1928 & 6725 & 3539 & 3186 & 6944 & 3878 & 3066 & 120 \\
\hline 1929 & 6520 & 3917 & 2603 & 6876 & 4132 & 2744 & -141 \\
\hline 1930 & 6229 & 3883 & 2346 & 6694 & 4284 & 2410 & -64 \\
\hline 1931 & 6053 & 4008 & 2045 & 6510 & 4501 & 2009 & 36 \\
\hline 1932 & 5842 & 4448 & 1394 & 5837 & 4786 & 1051 & 343 \\
\hline 1933 & 4435 & 7085 & -2650 & 5545 & 11450 & -5905 & 3455 \\
\hline 1934 & 4229 & 3782 & 447 & 4780 & 3410 & 1370 & -923 \\
\hline 1935 & 4888 & 3118 & 1770 & 5249 & 3882 & 1967 & -197 \\
\hline 1936 & 5350 & 3144 & 2206 & 5589 & 3223 & 2366 & -160 \\
\hline 1937 & 6405 & 3126 & 3279 & 6549 & 3557 & 2992 & 287 \\
\hline 1938 & 6323 & 2961 & 3362 & 6516 & 3483 & 3033 & 329 \\
\hline $1927-31$ & 32182 & 18929 & 13253 & 33974 & 20779 & 13195 & 58 \\
\hline $1932-34$ & 14506 & 15315 & -809 & 16162 & 19646 & -3484 & 2675 \\
\hline $1935-38$ & 22966 & 12349 & 10617 & 23903 & 14145 & 10358 & 259 \\
\hline
\end{tabular}

Примечание: Смертность в 1933 г. принята на 200 тыс. выме, чем в таблице, приведенной в [Андреев и др. 1993] в соответствии с размером поправки. В [ЦСУ 1964] дается для 1933 г. рядом с иифрой 19,7\% зачеркнутая цифра $22,7 \%$.

Источники: [Андреев и др. 1993: 40, 118; ЦСУ 1964].

Критикуя работу специалистов ЦСУ, Андреев и соавторы пишут: «Результатами этих расчетов иногда пользовались, но никогда их не публиковали. Публикации отсутствовали не только потому, что продолжали скрываться страшные размеры потерь от голода и сам факт катастрофы 1933 года, но и потому, что расчет всегда считался приближенным, признавался его сугубо оценочный характер и авторы расчета всегда требовали осторожности при его использовании. Кроме малообоснованных предположений 
о размерах недоучета смертей в разные годы, слабость расчета, как уже было сказано, состоит в том, что некритически использовались результаты переписей 1926 и 1939 гг., игнорировались итоги переписи 1937 г., а также предполагалось, что при неполном учете смертей существовал полный учет рождений» [Андреев и др. 1993: 40].

Относительно переписей замечание Андреева и соавторов совершенно справедливо, но не следует забывать, что до перестройки ни один советский автор, включая и вышеупомянутых, не вносил корректив в переписи населения. Неточно замечание, что результаты расчета Бекуновой и Родиной никогда не печатались. В СССР действительно не злоупотребляли публикацией демографических сведений $30-$ х годов, но всегда, когда такие данные были нужны (и разрешены), печатались материалы рассматриваемого расчета, как это принято ЦСУ, без упоминания авторов ${ }^{3}$.

Что касается точности полученных результатов, то скромность, безусловно, украшает сотрудников ЦСУ, но в своей пояснительной записке к расчету они ничего о приблизительности или оценочном характере полученных результатов не сообщают, зато указывают, на каком основании и каким способом сделаны соответствующие поправки, что, к сожалению, совсем не всегда делают авторы публикуемых расчетов:

«С этого года (1933) органы ЦСУ начали определять полноту полученного материала в ЗАГСо-месяцах. Что касается 1927-1932 гг., то для этих лет полнота собранных от ЗАГСов материалов была нами проверена по архивным материалам - годовым отчетам естественного движения населения по Ф 1-а, в котором давались подробные примечания по каким административным единицам - районам, округам, автономным областям, отсутствовали сведения. В свое время (в 1933 году и последующие годы) в отделе были исчислены за годы 1927-1931 и 1933-1935 годы, распространенные на всю территорию СССР итоги родившихся, умерших и естественного прироста, которые приведены в специальной брошюре (для служебного пользования). Эти итоги и были нами после проверки использованы для уточнения расчетов населения следующим образом: а) число родившихся и умерших за 1927-1931 и 1933-1935 гг. - были использованы распространенные данные из брошюры. б) за 1931-1932 г. распространенные итоги были исчислены путем применения процента полноты материалов за 1933 г. в) за 1936-1938 отчетные материалы. г) В указанные материалы в отношении умерших были внесены поправки за счет недоучета умерших, который был обнаружен при получении итогов переписи 1939 г. Полученные таким путем распространенные итоги естественного движения населения за весь межпереписной период дали следующие результаты (тыс. человек): число родившихся 70 122, число умерших 40 309, естественный прирост 29813.

Исчисленный таким образом итог естественного прироста (29 813 тыс.) не соответствует приросту, полученному на основании итогов переписей 1926 и 1939 - 23529

\footnotetext{
${ }^{3}$ Например: [Народонаселение стран мира 1978: 71] - данные о рождаемости за 1927-1938 гг.; [Население СССР 1974: 9] - числа родившихся и умерших за 1928, 1937, 1938 г.; [Население СССР 1975: 7] - численность населения 1929, 1937, 1938 гг.
} 
тыс. чел. Для увязки в вышеприведенные данные об умерших (40 309 тыс.) была внесена поправка в размере 6284 тыс. (29813-23529)» [ЦСУ 1964].

Мы видим, что замечание об отсутствии поправок на «недоучет рождений» неверно. И рождаемость, и смертность были увеличены в расчете ЦСУ почти одинаково. А потери населения (убыль сверх естественной смертности) справедливо относятся в расчете только к погибшим. Важно отметить, что тенденция изменения численности населения в расчете по модели Андреева и соавторов и ЦСУ очень близки (таблица 1). Хотя рождаемость и смертность в оценках ЦСУ и Андреева сильно различаются, разница между средними значениями этих показателей для относительно мирных периодов очень мала (1927-1931 гг. - 0,5\%, 1935-1938 гг. - 2,5\%). По отношению к численности населения в конце рассматриваемых периодов в первом случае различие составит $0,04 \%$, а во втором $-0,15 \%$. По сравнению с возможной ошибкой при подсчете рождений и смертей даже за один год это абсолютно незначимые величины. Правда, для катастрофического периода 1932-1934 гг. расхождение огромно - 83\%, но, как отмечают сами авторы, оно является не результатом, вытекающим из использованной модели, а внесено в модель экспертной оценкой.

Отсутствие расхождений в тенденции движения населения, кроме случаев, когда уровень смертности задается на основании дополнительных исторических свидетельств, делает ненужным использование модели Андреева-Дарского-Харьковой с заведомо высокими рождаемостью и смертностью, а позволяет ограничиться сведениями 1964 г., которые имеют еще и то огромное преимущество, что они хорошо согласуются со всем комплексом демографических данных по разным регионам страны.

Использование экспертной оценки для катастрофических лет совершенно верно. И не только для 1933 г., когда надежная статистика была утрачена. Следовало бы также увеличить смертность в 1930-1931 гг., поскольку в эти годы вне учета ЗАГСов оказалась высокая смертность высланных на север крестьян и потери казахов, бежавших с мест принудительной оседлости. Также следует внести поправки в данные 1937 и 1938 г., так как большинство жертв Большого террора, очевидно, не попали в официальный учет.

Кроме сведений о рождаемости, для расчета потерь населения необходимы данные о численности поколений мужчин и женщин в одногодичной группировке по переписям 1926 и 1939 гг. При этом важно, чтобы численность населения по переписям оценивалась примерно с одинаковой точностью. Поскольку перепись 1937 г. по способам проведения сильно отличалась от других, ее можно использовать лишь как дополнительный материал, уточняющий результаты следующей переписи. При этом перепись 1939 г. ставится многими исследователями, в том числе и Андреевым, Дарским и Харьковой, под подозрение, ее разработчиков обвиняют в преувеличении численности в угоду Сталину [Жиромская 1992: 7; Андреев и др. 1993: 33, 125]. Правда, удивительным образом, основной корпус переписи (число лиц, учтенных обычным порядком, перепись НКВД и армии и оценку численности в труднодоступных районах) под сомнение никто не ставит. Возражения вызывают лишь однопроцентная поправка и результаты обработки контрольных бланков. 
Введение однопроцентной поправки организаторами переписи серьезно не обосновано. Однако не приходится сомневаться, что множество людей случайно или умышленно не прошли перепись. Охотники, рыболовы, лесорубы, золотоискатели, командировочные, запойные пьяницы и другие группы жителей, на время отлучившиеся из дома. Их численность, очевидно, достигала многих сотен тысяч и часть из них физически не могли встретиться со счетчиком. Немало людей умышленно уклонялись от столкновения с государством.

1. Сектанты. В Ленинграде их насчитывалось 2,4 тыс., а в Ленинградской области - 3,2 тыс. В пропорции ко всей стране (на окраинах сектантов было больше, чем центре), получаем 170 тыс. человек.

2. Бродяги. По сведениям ленинградской статистики, из 13 тыс. жителей Ленинграда, не имевших постоянного ночлега, прошли перепись в 1926 г. только одна тысяча человек [Докладная записка... 1991: 223-227].

3. Преступники, недавно вышедшие из тюрьмы и пытающиеся туда не попасть. Только в 1934-38 гг. из ГУЛАГа было освобождено 1370 тыс. человек и бежали и не были пойманы 130 тыс. За 1930-36 гг. из кулацкой ссылки бежали и не были возвращены обратно около 400 тыс. человек [Земсков 2003: 16-43].

4. И наиболее многочисленная группа сельских жителей, беспаспортные беженцы из села. В ходе коллективизации они устремлялись из родного села, куда глаза глядят, прятались у родственников или знакомых в городе или другой деревне. В 1930-33 гг. около 2 млн крестьянских семей были разорены налогами или «самораскулачились», бросили землю и инвентарь и бежали из дома. Многие из них, не имея соответствующих документов, старались не попадаться на глаза представителям власти. Трудно оценить, какая часть этих изгоев не прошла перепись. Но представляется, что один процент не будет преувеличенной оценкой. Однако в нашем случае приходится отказаться от этой поправки, поскольку при расчете потерь необходимо стремиться к равной точности переписей, а в перепись 1926 г. подобных коррекций не вводилось.

Следует заметить, что заполнение контрольных бланков проводилось теми же самыми людьми в то же самое время, что и проведение переписи общим порядком. Так что, признавая их работу превосходной, странно без специального рассмотрения отбрасывать ее часть как недостоверную. В архиве сохранились таблицы разработки контрольных бланков 1939 г. Из них видно, какая огромная дополнительная работа была проделана при проведении и обработке переписи. Счетчики на каждого человека, встреченного вне дома, если не было уверенности, что он переписан, заполняли контрольный бланк, где указывался адрес места, где этот человек должен был пройти перепись, и места, где он встретился со счетчиком. Всего было заполнено 4567 тыс. контрольных бланков. Они были разосланы по местам проживания указанных лиц, сверены с картотекой прошедших перепись и со сведениями о проживающих по указанному адресу. В конечном итоге 1491 тыс. человек 
были включены в оценку численности наличного населения с контрольных бланков (таблица 2) .

Таблица 2. Оценка численности населения по переписи 1939 г., тыс. человек

\begin{tabular}{l|r|c|c|r}
\hline & $\begin{array}{c}\text { ЦСУ в } \\
\text { нашей } \\
\text { трактовке }\end{array}$ & $\begin{array}{c}\text { ЦСУ в трактовке } \\
\text { Андреева, Дарского, } \\
\text { Харьковой }\end{array}$ & $\begin{array}{c}\text { Андреев, Дарский, } \\
\text { Харькова }\end{array}$ & Максудов \\
\hline Учтено в общем порядке & 159137 & 159137 & 159137 & 159137 \\
$\begin{array}{l}\text { Переписано особым } \\
\text { порядком }\end{array}$ & 5839 & 5843 & 5843 & 5839 \\
Труднодоступные районы & 2330 & 2330 & 2330 & 2330 \\
Итого & 167306 & 167309 & 167309 & 167306 \\
$\begin{array}{l}\text { Поправка на неточность } \\
\text { счета }\end{array}$ & 1673 & 1689 & 505 & \\
Контрольные бланки & 1491 & 1140 & 637 & 1171 \\
Дополнительный учет & 87 & 419 & 419 & 87 \\
Численность населения & 170557 & 170557 & 168871 & 168564 \\
\hline
\end{tabular}

Источники: [Андреев и др. 1993: 31-33; ЦГАНХ. Ф. 1562].

Примечание: Небольшие расхождения возникают из-за округления данных до тысяч. 87 тыс. включены дополнительно при обработке переписи летом 1939 г.; 419 тыс.. Андреев и соавторы получили, вычитая из окончательной численности ЦСУ (170557 тыс.) предполагаемые ими числа лии, переписанных с контрольных бланков (1140 тыс.), и однопроцентную поправку (1689 тыс.). При этом они считают, что эта цифра (419 тыс.) «осталось необъясненной».

Андреев, Дарский и Харькова, подозревая, что результаты переписи 1939 г. подтасованы, предположили, что пропорция людей, включенных с контрольных бланков в 1939 г., должна быть такой же, как в 1959 г. (0,38\%). С этой гипотезой трудно согласиться. За 20 лет между переписями выросла численность городского населения, а сельского упала. Меньше стало сел, в них больше школ, лечебных заведений, появились средства быстрого передвижения (машины, мотоциклы, автобусы). Все это привело к облегчению поездок по делам, сокращению их продолжительности. Наивно было бы предполагать, что при этом сохранится постоянной пропорция между количеством людей, встретившихся счетчику вне дома, и численностью населения. Насколько неустойчив этот коэффициент, видно из того, как быстро сокращалась доля людей, записанных в ходе переписи с контрольных бланков: в 1939 г. - 0,88\%, в 1959 г. $-0,38 \%$, в 1970 г. - 0,14\%, в 1979 г. $-0,07 \%$.

Процесс заполнения и обработки контрольных бланков в 1939 г. представляется намного более тщательным, чем в 1959 г. Это видно из того, что в 1939 г. не были включены в переписные листы 160 тыс. человек, записанных на контрольные бланки, а в 1959 г. - всего 3 тыс.! При контрольном обходе в 1939 г. обнаружено только 87 тыс. человек, не

\footnotetext{
${ }^{4}$ Андреев и соавторы пишут: «Перепись 1939 года, с точки зрения счета населения, проводилась весьма тщательно. Все инструкции были нацелены на то, чтобы не пропустить ни одного человека. Дважды уточнялись списки домовладений, тщательно составлялся оргплан, в котором имелись предварительные оценки численности населения.» [Андреев и др. 1993: 32].

${ }^{5}$ [РГАЭ. Ф. 1562; Итоги Всесоюзной переписи населения 1959 года: 6-7; Итоги Всесоюзной переписи населения 1970 года 1972:4-5; Итоги Всесоюзной переписи населения 1979 года 1989: 5]. В 1979 г. опубликованная цифра 0,12\% включает и контрольный обход, в 1970 г. контрольные бланки дали примерно столько же, сколько контрольный обход.
} 
прошедших перепись, а в 1959 г. - 285 тыс. Однако, несмотря на высокую достоверность обработки контрольных бланков в 1939 г., я считаю возможным исключить из них одну категорию - лиц, не прошедших перепись, не найденных в переписных листах и неверно указавших адрес проживания. Казалось бы, их следовало внести в перепись, поскольку они встретились со счетчиком, заполнившим на них контрольный бланк. Так и поступили в конечном счете в 1939 и в 1959 г. ${ }^{6}$ Однако настораживает, что в одной из архивных таблиц в этой графе сказано: «Может быть включено в переписные листы». Эта формулировка предполагает, что может быть и не включено. Очевидно, составители таблицы имели какието аргументы за и против такого решения и перекладывали ответственность на начальство. Это сомнение профессионалов, хорошо знакомых с материалами, является, на мой взгляд, достаточным основанием для исключения указанной группы лиц из переписи. Численность населения по переписи 1939 г. составит таким образом 168559 тыс. человек (80 717 тыс. мужчин, 87842 тыс. женщин). Численность по переписи 1937 г. с поправкой на отсутствие в этой переписи контрольных бланков равна 162170 тыс. (77 771 тыс. мужчин и 84399 тыс. женщин).

Перепись 1926 г., по мнению большинства исследователей, была намного менее точной, чем 1939 г. Дело в том, что абсолютно полный учет населения не был главной задачей организаторов переписи. Их интересовали в первую очередь социальные и экономические условия жизни людей. Для того времени точность 1-2\% была вполне удовлетворительной. Однако падение рождаемости и высокая смертность в начале $30-\mathrm{x}$ годов сделали проблему оценки численности населения чрезвычайно болезненной для советского правительства. Это привело к уничтожению результатов переписи 1937 г. и необычайно высоким требованиям к точности переписи 1939 г. Используя для расчета потерь все три переписи, необходимо привести их примерно к одинаковой точности. Для этого в перепись 1926 г. было внесено несколько поправок.

1. Недоучет переписью детей в младших возрастах (0-4 года). Такую коррекцию вводили Ю.А. Корчак-Чепурковский, Лоример, Андреев с соавторами. Я также пришел к необходимости такой поправки, когда при расчетах передвижки поколений между переписями относительная убыль возрастов 0-4 года оказалась заметно меньше, чем у соседних когорт. Суммарная поправка составляет 1,5 млн. человек.

2. Перепись в 1926 г. продолжалась в городе 7 дней, а в селе - 2 недели. В результате крестьяне, не прошедшие перепись, могли на второй неделе переехать в районы, где перепись уже была проведена. Очень осторожная оценка числа лиц, неучтенных из-за погрешности этой методики проведения переписи, составила 500 тыс. человек.

3. Отсутствие контрольных бланков и контрольного обхода может быть компенсировано введением поправки в размере 0,5\% (740 тыс. человек). Это несколько меньше, чем с помощью контрольных мер было включено в перепись в 1939 г., поскольку эта поправка отчасти перекрывается другими коррекциями.

4. В Средней Азии и других мусульманских районах страны учет населения был неполным по нескольким причинам. Стойбища кочевников просто не попадали в сферу

\footnotetext{
${ }^{6}$ В 1939 г. включали не всех. Не включали лиц, которые отсутствовали в переписных листах, дали неверный адрес, но утверждали, что прошли перепись в другом месте [ЦСУ 1964].
} 
внимания переписчиков, ориентировавшихся на оседлое население. В то время продолжалась война с басмачами, которые прятались в пустыне или за границей и совершали оттуда неожиданные набеги. Численность басмачей составляла несколько десятков тысяч человек, но значительным было и число их сторонников среди местного населения. Также от переписи скрывали несовершеннолетних жен, вторых и третьих жен, а порой и маленьких детей. Общий недоучет по этим причинам принимаем в размере 150 тыс., хотя не исключено, что он был больше.

Таким образом, численность населения с учетом этих поправок составляет в 1926 г. 149918 тыс. (72 633 тыс. мужчин и 77285 тыс. женщин). Нельзя не задаться вопросом, почему же ученые в 1926 г. и позже не вносили соответствующие коррективы? Как уже отмечалось, в 1926 г. точность переписи казалась вполне удовлетворительной. Понимание ее неполноты возникло лишь после проведения последующих переписей, но в этот момент статистики были заинтересованы скорее в преуменьшении численности населения в 1926 г., чтобы как-то объяснить низкие результаты переписи 1937 г.

Коррекция переписей с попыткой достижения примерно одинаковой точности существенно меняет представление о размерах потерь населения в 30-е годы. Прирост населения в 1926-1939 гг., по традиционным сведениями ЦСУ, был равен 23529 тыс. человек (170 557 тыс. - 147028 тыс.). С учетом внесенных поправок в численность населения по переписям 1939 и 1926 г. прирост составит (168 564 тыс. - 149918 тыс. $=18$ 646 тыс. человек). Разница составляет 4883 тыс. человек. На эту величину возрастет и оценка потерь за рассматриваемый период. Как было отмечено выше, ЦСУ в 1964 г. оценивало потери в 6284 тыс. С найденной поправкой они возрастают до 11167 тыс. человек. Эта цифра является приблизительной, но она демонстрирует, что имеющиеся оценки потерь коллективизации должны заметно возрасти.

\section{ЗАКЛЮЧЕНИЕ}

Рассмотрение методики обработки контрольных бланков в 1939 г. позволило надежнее рассчитать численность населения на дату переписи и внести уточнения в материалы переписей 1926, 1937, 1939 г. Численность населения в 1939 г. снизилась на 1\%, в 1937 г. осталась почти без изменений, а в 1926 г. увеличилась почти на 2\%. Часть этой поправки связана с недоучетом численности детей, другая вызвана отсутствием в 1926 г. контрольных мероприятий и разной продолжительностью этой переписи в городе и деревне.

Совместное рассмотрение переписей 1926, 1937 и 1939 г. с приведением их к приблизительно одинаковой точности позволит оценить демографическим путем размеры потерь населения в годы коллективизации.

\section{ЛИТЕРАТУРА}

Андреев Е.М., Л.Е. Дарский, Т.Л. Харькова (1993). Население Советского Союза. $1922-$ 1991. М.: Наука. 
Демографическая модернизация России 1900-2000 (2006) / Под редакцией А. Вишневского. М.: Новое издательство.

Докладная записка Ленинградского УНХУ о недоучете населения в ходе Всесоюзной переписи населения 1937 г. по Ленинграду и Ленинградской области (1991)// Всесоюзная перепись населения 1937 г. Краткие итоги. (Сборник документов). М.

Жиромская В.Б. (1992). Всесоюзная перепись населения 1939 г. История проведения, оценка достоверности // Всесоюзная перепись населения 1939 года. Основные итоги. M.

Земсков В.Н. (2003). Спецпоселенцы в СССР 1930-1960. М.

Итоги Всесоюзной переписи населения 1959 года (1962). М.: Статистика

Итоги Всесоюзной переписи населения 1970 года (1972). Т.1 М.: Статистика

Итоги Всесоюзной переписи населения 1979 года (1989). Т.1. М.: Статистика

Трагедия советской деревни. Коллективизация и раскулачивание. Документы и материалы. 1927-1939 (2001). Т. 3. Конец 1930 - 1933. М.: РОССПЭН

Максудов С. (1987). Дискуссия на Западе о потерях советского населения в годы коллективизации. Минувшее, № 4: 369-392. Париж.

Народное хозяйство СССР (1956). Статистический сборник. М.: Статистика.

Народонаселение стран мира (1978). Справочник. М.: Статистика.

Население СССР (1974). Справочник. М.: Статистика.

Население СССР 1973 (1975). Статистический сборник. М.: Статистика.

РГАЭ. Ф. (1562). ОП. 329. Ед.хр. 144.

Уиткрофт С. (2001). О демографических свидетельствах трагедии советской деревни в 1931-1933 гг. // Трагедия советской деревни. Коллективизация и раскулачивание. Документы и материалы. 1927-1939. М.: РОССПЭН. Т. 3: 866-887.

ЦГАНХ. Ф. (1562). Оп. 336-337. Ед.хр. 95.

ЦСУ (1964). Папка №2. Архив Госкомстата.

Conquest R. (1986). The Harvest of sorrow: Soviet collectivization and the terror-famine. Oxford University Press.

Davies R.W., S.G. Wheatcroft (2004). The years of hunger: soviet agriculture, 1931-1933. Great Britain. New York: Palgrave Macmillan.

Lorimer F. (1946). The population of the Soviet Union: History and prospects. Geneva. League of Nations. 


\title{
SOME PROBLEMS OF ASSESSING POPULATION LOSSES DURING COLLECTIVIZATION \\ SERGEI MAKSUDOV
}

\author{
Sergei Maksudov. Davis Center for Russian and Eurasian Studies at Harvard University. USA. \\ E-MAIL: babyonys@fas.harvard.edu. \\ DATE RECEIVED: June 2015 .
}

\begin{abstract}
After the opening of the Soviet archives in the late 1980s, many researchers found the results of the 1939 census unreliable. Those who conducted the census recalled the sad fate of those who had organised the census of 1937, which was found to be flawed. They understood that the government wanted to see a large population represented in their results.
\end{abstract}

\begin{abstract}
That's why they decided to falsify the results. Our research shows that the major efforts that were put into a precise execution of the census did not go to waste. And the hundreds of census-takers, who were expected to find every person who lived in their district, tried their best to carry out their work with care. Study of the archive materials reveal how, during processing, results were handed to the government and made public by the country's leadership.
\end{abstract}

The study shows that the census of 1939 was accurate, and more reliable than those which had come before and after. And even a one percent adjustment to the figure which represents the population size, carried out seemingly without good reason, is not an error, because the number of people who avoided the census (due to their criminal past, lack of local registration, illness or other reasons) certainly exceeds $1 \%$.

\begin{abstract}
But any change to the estimate of the population losses should be avoided, since it was not included in prior censuses, and to acquire reliable results it is necessary that the data used have equal accuracy. In our census we also chose not to include those who met with the census-taker outside their home, and then wrongly stated their place of permanent residence in the test form. Thus, the size of the population in the 1939 census is considered at 2 million less than in the TSSU's Soviet-era publications. In order to reach the same approximate level of reliability across the census results it was necessary to include certain corrections in the census of 1926 (due to lack of test forms, varying census lengths in cities and villages, and also due to undercount in the census of underage children) and 1937 (due to a different method of execution). The changes made allow for a more reliable assessment of the USSR's losses from collectivisation and repression in the period 1929-1939.
\end{abstract}

Key words: population census, collectivization, population losses

\section{REFERENCES}

Andreev E.M., L.Yu. Darskiy, T.L. Kharkova (1993). Naseleniye Sovetskogo Soyuza. 19221991 [The population of the Soviet Union. 1922-1991]. Moscow: Nauka.

Conquest R. (1986). The Harvest of sorrow: Soviet collectivization and the terror-famine. Oxford University Press.

Davies R.W., S.G. Wheatcroft (2004). The years of hunger: soviet agriculture, 1931-1933. Great Britain. New York: Palgrave Macmillan.

Demograficheskaya modernizatsiya Rossii 1900-2000 [Demographic modernization of Russia 1900-2000] (2006) / A. Vishnevsy, ed. Moscow: Novoye izdatel'stvo.

Dokladnaya zapiska Leningradskogo UNKHU o nedouchete naseleniya v khode Vsesoyuznoy perepisi naseleniya 1937 g. po Leningradu i Leningradskoy oblasti [Staff report of Leningrad 
UNKhU about the population underwstimation in the 1937 All-Union census in Leningrad and Leningrad region] (1991) // Vsesoyuznaya perepis' naseleniya 1937 g. Kratkiye itogi. (Sbornik dokumentov) [Brief results (Collection of documents)]. Moscow.

Itogi Vsesoyuznoy perepisi naseleniya 1959 goda [The results of the All-Union census of 1959] (1962). Moscow: Statistika

Itogi Vsesoyuznoy perepisi naseleniya 1970 goda [The results of the All-Union population census of 1970] (1972). T.1 Moscow: Statistika

Itogi Vsesoyuznoy perepisi naseleniya 1979 goda [The results of the All-Union population census of 1989] (1989) . T.1. Moscow: Statistika

Lorimer F. (1946). The population of the Soviet Union: History and prospects. Geneva. League of Nations.

Maksudov S. (1987). Diskussiya na Zapade o poteryakh sovetskogo naseleniya v gody kollektivizatsii [Discussion in the West about the Soviet population losses during the collectivization]. Minuvsheye, № 4: 369-392.

Narodnoye khozyaystvo SSSR [The national economy of the USSR] (1956). Statisticheskiy sbornik. Moscow: Statistika.

Narodonaseleniye stran mira [Population of the world] (1978). Spravochnik. Moscow: Statistika.

Naseleniye SSSR [Population of the USSR] (1974). Spravochnik. Moscow: Statistika.

Naseleniye SSSR 1973 [Population of the USSR in 1973] (1975). Statisticheskiy sbornik. Moscow: Statistika.

RGAE [Russian State Archive of Economy]. F. 1562. Op. 329. Yed.khr. 144.

Tragediya sovetskoy derevni. Kollektivizatsiya i raskulachivaniye. Dokumenty i materialy. 1927-1939 [The tragedy of the Soviet countryside. Collectivization and dispossession. Documents and materials. 1927-1939] (2001). T. 3. Konets 1930 - 1933. Moscow: ROSSPEN.

TSGANKH [Central State Archive of the Soviet economy]. F. 1562. Op. 336-337. Yed.khr. 95.

TSSU [Central Statistical Office] (1964). Papka №2. Arkhiv Goskomstata.

Wheatcroft S. (2001). O demograficheskikh svidetel'stvakh tragedii sovetskoy derevni v 1931$1933 \mathrm{gg}$. [On the demographic evidence of the tragedy of the Soviet countryside in 19311933 gg] // Tragediya sovetskoy derevni. Kollektivizatsiya i raskulachivaniye. Dokumenty i materialy [The tragedy of the Soviet countryside. Collectivization and dispossession. Documents and materials.]. 1927-1939. Moscow: ROSSPEN. T. 3: 866-887.

Zemskov V.N. (2003). Spetsposelentsy v SSSR 1930-1960 [Deportees in the USSR 1930-1960]. Moscow.

Zhiromskaya V.B. (1992). Vsesoyuznaya perepis' naseleniya 1939 g. Istoriya provedeniya, otsenka dostovernosti [1939 All-Union census. History of implementation, assessment of reliability] // Vsesoyuznaya perepis' naseleniya 1939 goda. Osnovnyye itogi [1939All-Union census. Main results]. Moscow. 